\title{
Shared Leadership and Team Creativity: A Social Network Analysis in Engineering Design Teams
}

\author{
Qiong $W u^{* 1}$, Kathryn Cormican ${ }^{1}$
}

\begin{abstract}
This research explores the relationship between shared leadership and creativity in engineering design teams. To do this, a social network perspective was adopted using four measures to assess key elements of shared leadership networks. These are (a) network density, (b) centralization, (c) efficiency and (d) strength. Data was collected from a sample of 22 engineering design teams who adopt a shared leadership approach. Our results support previous findings that the density of a shared leadership network is positively related to team creativity. In contrast, we learned that centralization exerts a negative influence on it. Moreover, while we found that there is no evidence to support a positive correlation between efficiency and team creativity, we demonstrate an inverted U-shaped relationship between strength and team creativity in a shared leadership network. These findings are important because they add to the academic debate in the shared leadership area and provide valuable insights for managers.
\end{abstract}

Keywords: shared leadership; social network analysis; team creativity; engineering design teams

Submitted: March $25^{\text {th }} 2016 /$ Approved: Approved: June $7^{\text {th }} 2016$

\section{Introduction}

High-quality leadership is essential to team effectiveness (Kozlowski \& Bell, 2003; Pearce et al., 2004). In fact, some scholars have argued that it is the most decisive enabling factor (Zaccaro et al., 2002). However, the majority of existing research in the area of team leadership has concentrated narrowly on the influence and behavior of individual team leaders who occupy formal leadership positions, therefore largely ignoring leadership roles provided by team members (Kozlowski \& Bell, 2003). In recent years, the concept of shared leadership has emerged in the literature. It is defined as "leadership that emanates from the members of teams and not simply from the appointed team leader" (Pearce \& Sims, 2002). Shared leadership, occurs when all team members are fully engaged in the leadership process instead of being led by a solitary designated leader (Seers et al., 2003). Studies have found that shared leadership has proven to produce greater effectiveness (Muethel \& Hoegl, 2013), to be a significant predictor of team outcomes (Shane Wood \& Fields, 2007) and team performance (Ensley et al., 2006), and it is related to an increase in the quality of problem solving skills (Pearce, 2004). Thus, we are witnessing an evolutionary shift in leadership responsibilities from a single appointed manager to that of many team members. Hooker and Csikszentmihalyi (2003) assert that shared leadership is now becoming the new dominant organizational form. There are two key reasons for this. Firstly, because in the present complex working environment, it is difficult for a sole leader, despite the level of experience or education background, to have sufficient knowledge and skills to carry out all leadership functions required 0 . Secondly, high performance teams rely on knowledge workers who demand a participative approach to decision making (Bergman et al., 2012). As a consequence, attention has begun to concentrate on this shift from solitary leaders to that of shared leadership as a better way of leading high performance teams (Ensley et al., 2006; Mehra et al., 2006).

Table 1 synthesizes recent studies that have been conducted in the area of shared leadership. It illustrates the various contexts that recent research studies have been conducted, the relationships between shared leadership and team outcomes, as well as the methods that researchers have used to measure shared leadership. Specifically, looking at the first column in Table 1, we can see the different contexts in which shared leadership has been studied. This includes change management teams (Pearce \& Sims, 2002), independent professional teams (Muethel \& Hoegl, 2013), consulting teams (Carson et al., 2007), sports teams (Fransen et al., 2015), virtual teams (Pearce et al., 2004), field-based sales teams (Mehra et al., 2006), top management teams (Ensley et al., 2006), product development teams (Cox et al., 2003), and extreme actions team (Klein et al., 2006). The second column of Table 1 depicts the correlations between shared leadership and team effectiveness (Cox et al., 2003; Muethel \& Hoegl, 2013; Pearce \& Sims, 2002; Pearce et al., 2004); team performance (Carson et al., 2007; Ensley et al., 2006; Mehra et al., 2006), team leading roles (Fransen et al., 2015) and team dynamic delegation (Klein et al., 2006). Lastly the third column of the table synthesizes the methods used for measuring shared leadership. We found that prior work has mostly focused on aggregating team members' ratings of their perception of the extent to which leadership responsibilities are shared. For example, Pearce et al. (2004) study on virtual teams and Ensley et al. (2006) work on new venture top management teams both used ratings (aggregated to team level) on behavioral scales for four leadership strategies namely directive, empowering, transactional and transformational.

(1) College of Engineering and Informatics, National University of Ireland, Galway

*Corresponding author: Q.Wu1@nuigalway.ie 
Table 1: Previous research of shared leadership related to contexts, correlations, and methods

\begin{tabular}{|c|c|c|c|}
\hline Contexts & Correlations & Methods & References \\
\hline Change management teams & Team effectiveness & Aggregating ratings & Pearce and Sims (2002) \\
\hline Independent professional teams & Team effectiveness & Not defined & Muethel and Hoegl (2013) \\
\hline Consulting teams & Team performance & Social network analysis & Carson et al. (2007) \\
\hline Sports teams & Leading roles & Social network analysis & Fransen et al. (2015) \\
\hline Virtual teams & Team effectiveness & Aggregating ratings & Pearce et al. (2004) \\
\hline Field-based sales teams & Team performance & Social network analysis & Mehra et al. (2006) \\
\hline Top management teams & Team performance & Not defined & Ensley et al. (2006) \\
\hline Product development teams & Team effectiveness & Not defined & Cox et al. (2003) \\
\hline Extreme actions teams & Dynamic delegation & Aggregating ratings & Klein et al. (2006) \\
\hline
\end{tabular}

An analysis of the extant literature reveals some gaps in the research that warrant further investigation. Most notably Bergman et al. (2012) have suggested that future studies in the area of shared leadership should pay attention to aspects beyond traditional team performance metrics. Hooker and Csikszentmihalyi (2003) ascertain that shared leadership may offer both timely and useful assistance in promoting the creative potential of engineering design teams. However, we notice a dearth of studies focusing on the correlation between shared leadership and team creativity. Furthermore, there is lack of empirical analysis and practical arguments for the influence of shared leadership on team creativity. It seems that this important issue should be addressed.

Engineering design comprise knowledge workers from many different disciplines and requires complementary skills to execute innovative efforts. Such teams focus on problem solving (Lessard \& Lessard, 2007) where creativity plays a vital role (Gehani, 2011). Indeed, the creative capacity of the team is lauded to consolidate the platform of organizational innovation (Pandey \& Sharma, 2009) and mold the foundation for positive team outcomes (Kratzer et al., 2010). Additionally, according to Ensley et al. (2006), the creative process is accelerated when workers are encouraged to collaborate with peers and to autonomously self-direct. In light of this, our research aims to expand the current debate on shared leadership to engineering design teams. We found that prior work has failed to capture the relational nature of shared influence among team members. Therefore, using social network theory, (see Carson et al. (2007), Mehra et al. (2006), and Small and Rentsch (2015)), we advance a more complete conceptualization of the relational phenomenon of shared leadership and use social network analysis to better capture patterns of influence. Consequently, the goal of our research is to explore the correlations between shared leadership and team creativity in engineering design teams using social network analysis. To do this, we create a conceptual model of our study and propose four key hypotheses about the correlations between key metrics in shared leadership networks and team creativity. We develop binary matrices and sociograms to plot the interactions between the team members in each of the sample teams. Finally, we conduct inferential statistical tests using correlation analysis and hierarchical regression analysis to examine our proposed hypotheses.
The remainder of the paper is organized as follows: in section 2, a synthesis of the relevant literature is presented which focuses on shared leadership and social network analysis. From this, key hypotheses are generated. Section 3 presents the research methodology employed in this study. This describes the data collection process, sampling method, measuring process as well as the data analysis process. Finally, the research findings are discussed, limitations of the study are identified and the final conclusions are drawn.

\section{Literature review and hypotheses generation}

\subsection{Shared leadership}

Traditional models of leadership in organizations emphasize hierarchy where a single appointed leader is responsible for communicating visions and controlling operations (Cox et al., 2003; Shane Wood \& Fields, 2007). However, with the pervasive presence of self-managed teams (Latora \& Marchiori, 2001), team members tend to share leadership responsibilities, with visions, plans and actions emanating from many members within a team as opposed to a single individual. Shared leadership, thus, is attracting more scholars, and has been defined in many different ways. It is considered in terms of team processes during which team members engage in the leadership role and interact with each other to achieve organizational goals (Ensley et al., 2006). It is also characterized by the serial emergence of official and unofficial leaders (Pearce, 2004). Moreover, it refers to a mutual influence process that is dynamic, simultaneous, on-going, as well as multidirectional (Fletcher and Kaufer 2003). Carson et al. (2007) propose that shared leadership should not be considered in a narrow sense where the focus is on specific leadership traits, characteristics or behaviors. But rather they contend that a wider perspective should be adopted where shared leadership is considered in terms of multiple influencing resources within teams. Building on these ideas, we can say that shared leadership refers to the widespread influence that arises from the distribution of leadership responsibility among team members. Moreover, based on the research of Shane Wood and Fields (2007), we present a comparative analysis of traditional leadership and shared leadership characteristics (see Table 2). 
Table 2. Comparative analysis of traditional leadership and shared leadership

\begin{tabular}{lll}
\hline Dimension & Traditional leadership & Shared leadership \\
\hline Ways of leading & Centralized vision (Pearce \& Conger, 2002) & Self-led (Cox et al., 2003) \\
\hline Communication \& information flow & Vertical and top-down (Shane Wood \& Fields, 2007) & Lateral and interactive (Hackman \& Johnson, 2013) \\
\hline Decision-making process & Decisions made by the appointed leader (Cox et al., 2003) & Members involve in decision making process (Bergman et al., 2012) \\
\hline Members' behaviors & $\begin{array}{l}\text { Dependent and instructed (Pearce \& Sims, 2002); } \\
\text { leader (Day et al., 2004) }\end{array}$ & $\begin{array}{l}\text { Autonomous (Mehra et al., 2006); Social integration (Pearce, } \\
\text { 2004) }\end{array}$ \\
\hline Team's behaviors & Responsive to the leader's expectations (Seers et al., 2003) & Cooperative and consensus-driven (Bergman et al., 2012) \\
\hline Organization's vision source & Top down (Pearce \& Conger, 2002) & Shared vision stemmed from team (Pearce \& Conger, 2002) \\
\hline Intragroup environment & Tend to hierarchy (Pearce \& Conger, 2002) & $\begin{array}{l}\text { Less conflict, higher cohesion and intragroup trust (Bergman } \\
\text { et al., 2012) }\end{array}$ \\
\hline
\end{tabular}

\subsection{Social network analysis}

Shared leadership has been regarded as a relational phenomenon that involves patterns of reciprocal influence within a team. Therefore many studies have used social network analysis techniques to measure it (e.g., Mehra et al., 2006; Small \& Rentsch, 2015). This approach is appropriate for two main reasons. First of all, social network analysis is an intrinsically relational method used to examine relationship patterns; it provides methods to model the interpersonal influences and uses network graphs to identify patterns of leadership. Secondly, social network analysis is lauded to better preserve information about actual distributed leadership patterns within teams (Balkundi \& Kilduff, 2006). In this research, we use social network analysis to assess the characteristics of shared leadership networks by employing four measurements: density, centralization, efficiency and strength. Table 3 lists the concepts and application of these four measures based on an analysis of the literature of social network analysis. We note that previous studies of shared leadership has applied density (Carson et al., 2007; Lee et al., 2015), centralization (Mehra et al., 2006; Small \& Rentsch, 2015) or a combination of these two to measure the distribution of leadership functions among team members (Pastor \& Mayo, 2002). However, we notice a lack of research on strength and efficien$c y$ in shared leadership networks. Strength and efficiency, have been widely applied to communication networks (Kratzer et al., 2010; Yuan et al., 2009). Communication is regarded as an essential antecedent and a critical success factor to shared leadership (Hoppe \& Reinelt, 2010). The willingness of team members to communicate closely aligns with their willingness to interact with peers which in turn can influence the effectiveness of shared leadership in a team (Hackman \& Johnson, 2013). As a consequence, efficiency and strength should also be examined in shared leadership networks in order to help us understand a new perspective and enable a deeper analysis.

Table 3. Concepts and applications of four measurements of social network analysis

\begin{tabular}{llll}
\hline Measurements & Concepts & Applications & References \\
\hline Network density & $\begin{array}{l}\text { Measures the compactness or closeness of team member } \\
\text { interactions with each other. }\end{array}$ & Shared leadership & $\begin{array}{l}\text { Carson et al. (2007); Lee et al. } \\
(2015)\end{array}$ \\
\hline Network centralization & $\begin{array}{l}\text { Measures the extent to which team members rely on a small } \\
\text { concentrated number of people. }\end{array}$ & Shared Leadership & $\begin{array}{l}\text { Mehra et al. (2006); Small and } \\
\text { Rentsch (2015) }\end{array}$ \\
\hline Network Efficiency & $\begin{array}{l}\text { Measures the amount of contact among team members. This } \\
\text { implies how much information flow is in a network. }\end{array}$ & Communication & Kratzer et al. (2010) \\
\hline Network Strength & $\begin{array}{l}\text { Measures the frequency of contact among team members. This can } \\
\text { influence how often information is exchanged. }\end{array}$ & Communication & Networks \\
\hline
\end{tabular}




\subsubsection{Network density}

Density in a leadership network describes the percentage of actual leadership ties relative to all potential leadership ties among team members (Carson et al., 2007). When more group members perform leadership responsibilities more leadership ties emerge which then increases the network density. Lee et al. (2015) used network density to measure shared leadership by studying its effects on knowledge sharing as well as the subsequent influence on team creativity. Their results illustrate that knowledge sharing plays a partially mediating role between shared leadership and team creativity. In other words, the process of knowledge sharing is boosted in shared leadership networks with high levels of density, where more team members perform leadership behaviors. During this process, members can also share their own expertise and integrate these in new ways. Integration is likely to increase the cross-fertilization of viewpoints and promote the probability of team creativity. On the contrary, low levels of density in shared leadership networks with fewer links among team members hinders knowledge sharing and acts as a barrier to creativity. Therefore we propose:

Hypothesis 1: Density in a shared leadership network is positivity related to team creativity.

\subsubsection{Network centralization}

Centralization represents the extent to which one or several team members are predominant in a shared leadership network (Sparrowe et al., 2001). The theoretical basis for proposing a hypothesis that there is a negative correlation between shared leadership network centralization and team creativity, is extracted from differences among dependence, independence and interdependence presented by Molm (1994). Those arguments imply that lower levels of network centralization can facilitate interdependence among team members that in turn contributes to co-operation. Group members in interdependent network relationships are different from those in dependent relationships where team members have fewer interactions with each other. Individuals in interdependent networks tend to have more communication and cooperation with their peers. As network centralization represents the degree to which exchange relations are focused on a small number of actors, the higher the centralization in a shared leadership network, the less interdependence, and thus the less cooperation that exists. It is the cooperation among team members that fosters exchange of knowledge, and encourages participation of individuals. This in turn increases the chances of interaction among networks and thus raises the possibility of team creativity. On the basis of these studies, the following hypothesis is proposed:

Hypothesis 2: Centralization in a shared leadership network is negatively related to team creativity.

\subsubsection{Network efficiency}

According to Burt (2009), "network efficiency is the first design principle of an optimized network". Thus when measuring shared leadership networks, we should consider this factor. In light of this, we propose that efficiency in a shared leadership network exerts a positive influence on team creativity. The main argument behind it is that leadership interactions among team members can be confined by the available energy and time, yet a highly efficient network generates less waste of energy and time, and, consequently, more would be used to transform information into new ideas. Moreover, high network efficiency means that teams have more access to various non-overlapping information flows and mutually unconnected partners (Kratzer et al., 2010), which boosts the diversity of knowledge and then increases the possibility of creativity. As a consequence, we present:

Hypothesis 3: Efficiency in a shared leadership network is positivity related to team creativity.

\subsubsection{Network strength}

Network strength, refers to the frequency of contacts among team members which can affect how often information is exchanged within the team (Kratzer et al., 2010). High frequency means that individuals can communicate and exchange their expertise more regularly, which would thus raise the level of creativity in the team. Additionally, frequent contact can promote internal trust among team members. Trust was found to contribute to knowledge sharing and collaboration (Mcevily et al., 2003). Flap and Völker (2001) contend that team performance benefits from teams with a high level of trust and collaboration. In this situation, team members are likely to be more creative. However, it should be noted that some researchers have argued that too much interaction can impede innovation (Baer, 2010). In this view when there is much interaction within a team, opinions and perspectives can become very similar and even redundant, which could exert a negative influence on the creative process. Recently, Kratzer et al. (2010) suggested that there may be a curvilinear relationship between strength and creativity. This means that with the increase in network strength, team creativity shows a downward trend after rising to an optimum level (i.e. an inverted U-shaped relationship), which implies that a certain amount of contact among team members in shared leadership network can promote team creativity, whereas too much communication would exert a hindering effect on it. Consequently in this study we used network strength to help assess frequency of contact in shared leadership networks and also tested this curvilinear relationship:

Hypothesis 4: There is an inverted U-shaped relationship between strength and team creativity in shared leadership networks.

\section{Methodology}

\subsection{Study setting}

We collected data from two types of engineering design teams - chemical engineering design teams and mechanical engineering design teams who adopt a shared leadership approach. 173 respondents from 24 teams initially participated in our study, which accounts for a response rate of $89 \%$. The data collection process lasted almost three months, during which questionnaires were distributed via email to teams in order to measure the level of shared leadership and the level 
of creativity within the teams. As results of network analysis are more sensitive to data omission than others a within-team response rate of $90 \%$ is required (Maloney et al., 2010). In light of this, all data from teams with a response rate below $90 \%$ was excluded. Finally, our data analysis relied on 22 teams which accounted for a total of 158 participants. The characteristics of the sample are shown in Table 4.

Table 4. Attributes of the sample

\begin{tabular}{|c|c|c|c|c|c|c|c|c|c|c|}
\hline \multirow[b]{2}{*}{ Sample } & \multicolumn{2}{|c|}{$\begin{array}{l}\text { Total amount } \\
\text { (respondents) }\end{array}$} & \multicolumn{2}{|c|}{ Average age (years) } & \multicolumn{2}{|c|}{ Average tenure (years) } & \multicolumn{2}{|c|}{ Team number } & \multicolumn{2}{|c|}{ Team size (persons) } \\
\hline & \multicolumn{2}{|c|}{158} & \multicolumn{2}{|c|}{32.8} & \multicolumn{2}{|c|}{3.7} & \multicolumn{2}{|c|}{22} & \multicolumn{2}{|c|}{7.2} \\
\hline & Male & Female & $<$ Bachelor & Bachelor & Master & $\mathrm{PhD}$ & China & England & German & Others \\
\hline
\end{tabular}

\subsection{Measures}

The measurement process can be divided into three parts. It is illustrated in Figure 1. The first is to examine shared leadership networks in terms of their structure and properties. During this process, we developed binary matrices to identify the level of shared leadership in each of the teams, we employed sociograms to visually analyze what shared leadership networks look like for each participating team, and then we calculated the coefficients of network density, centralization, efficiency and strength in order to reveal each of the shared leadership networks' properties. Secondly, we measured team creativity from four angles, novelty, originality, usefulness and flexibility. The third part introduced two control variables (e.g. team size and team experience) in order to eliminate their influence during the data analysis. Specific details of the measurement process are presented below.

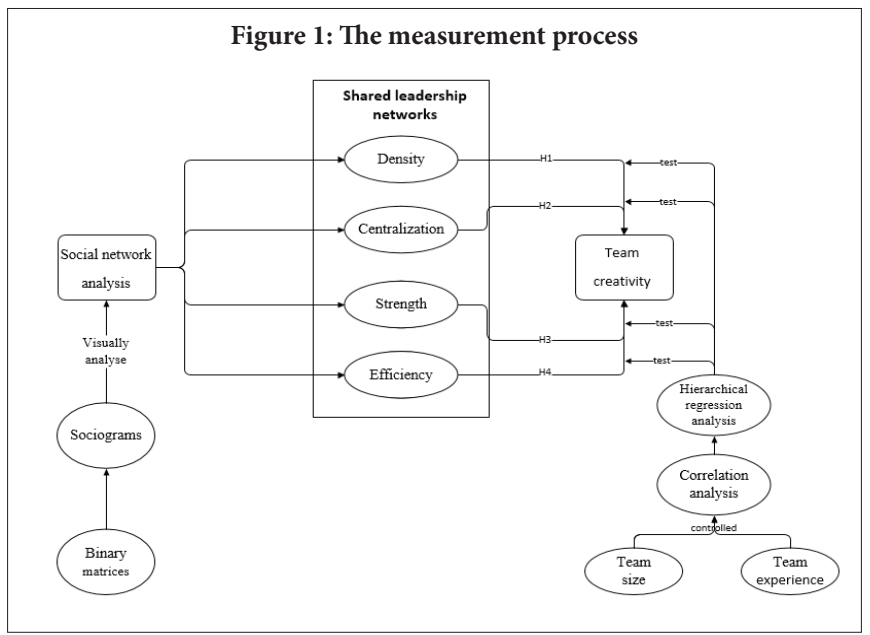

\subsubsection{Shared leadership networks}

In order to assess the distribution of leadership responsibilities from each of the 22 engineering design teams, a roster method was used to collect data following the procedures of the classic sociometric work of Stogdill (1948) on leadership in teams. Each team was provided with a list of names (in alphabetical order) representing all members of the team and a list of leadership responsibilities based on the research of Pastor and Mayo (2002). Respondents were required to select the names of individuals that they perceived to perform leadership responsibilities. The data collected from participants were analyzed using the following procedures.

Binary Matrices: Binary matrices are useful because they can represent the presence or absence of relationships between pairs of elements in a system. In our study they are used to measure the level of leadership responsibilities for each participant in the study relative to another. To do this, we arranged data from 22 teams in separate $\mathrm{g}^{\star} \mathrm{g}$ matrices ( $\mathrm{g}$ is the total number of actors in one network) and used this to identify and describe shared leadership. To be specific, in each matrix, cell would be given the value of 1 if $i$ perceived $j$ perform 3 or more than 3 leadership responsibilities (range from 0 to 6); otherwise, can be deemed as 0 .

Sociograms. A sociogram is a graphical representation of the social links that each team member has. It is used in this study to visually depict the structure of each network from the codes in the binary matrices for each team. This visual analysis can also be used to clarify the overall network topology and reliably recognize central nodes (see Freeman, 2004). Figure 2 below provides an example of a sociogram developed by NodeXL. It represents a mechanical engineering design team comprising 11 members. As shown in this figure, almost no members are central in this network and they are all nearly equally distributed.

Figure 2: One example of shared leadership sociogram in this study

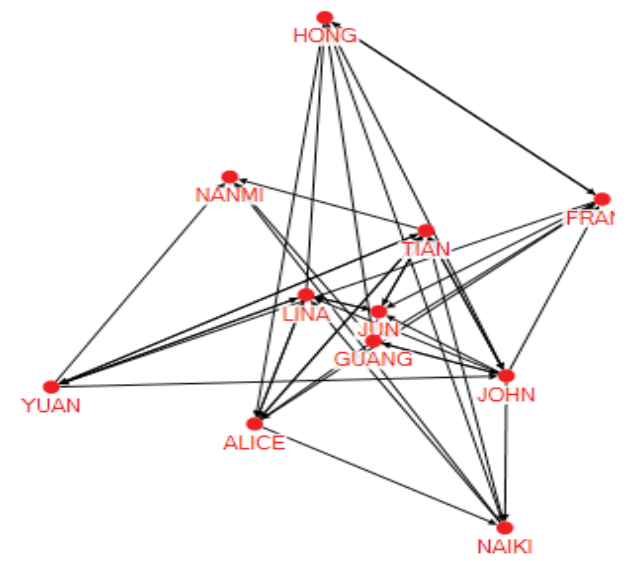


The last procedure is to quantify shared leadership networks by calculating the coefficients of network density, centralization, efficiency and strength for each sociogram. The value of all coefficients vary between 0 and 1 .

Network Density. The coefficient of network density was calculated by the sum of all direct links (L), and then dividing by the number of all potential direct links that could have emerged (Wasserman \& Faust, 1994). In this research the coefficient was computed by Ucient Software (Borgatti et al., 2002).

$$
\mathrm{ND}=\frac{\mathrm{L}}{\mathrm{g}(\mathrm{g}-1)} \text { Eq. (1) }
$$

( $\mathrm{g}$ is the total amount of team members; $\mathrm{L}$ is the sum of all links)

Network Centralization. Based on a mathematical definition of centralization proposed by Freeman (1979), centralization can be measured using Eq. (2). We used Ucinet software to compute this parameter (Borgatti et al., 2002).

$$
\mathrm{NC}_{\mathrm{A}}=\frac{\sum_{i=1}^{g}\left[\mathrm{C}_{\mathrm{A}}\left(\mathrm{n}^{*}\right)-\mathrm{C}_{\mathrm{A}}\left(\mathrm{n}_{\mathrm{i}}\right)\right]}{\operatorname{Max} \sum_{i=1}^{\mathrm{g}}\left[\mathrm{C}_{\mathrm{A}}\left(\mathrm{n}^{*}\right)-\mathrm{C}_{\mathrm{A}}\left(\mathrm{n}_{\mathrm{i}}\right)\right]} \text { Eq. (2) }
$$

$\left(C_{A}\left(n_{i}\right)\right.$ is a centrality index of one member; $C_{A}\left(n^{*}\right)$ is the greatest index among it; $g$ is the total amount of members.)

Network Efficiency. Our study used the measurement of Burt (2009) to calculate network efficiency as shown in Eq. (3).

$$
\mathrm{NE}\left(\mathrm{n}_{\mathrm{i}}\right)=\frac{\Sigma_{\mathrm{j}}\left[1-\Sigma_{\mathrm{q}} \mathrm{P}_{\mathrm{iq}} \mathrm{M}_{\mathrm{jp}}\right]_{\mathrm{N}}}{\mathrm{N}} \mathrm{Eq} \cdot \text {. (3) }
$$

( $\mathrm{N}$ is the total amount of members; $\mathrm{P}_{\mathrm{iq}}$ is interaction with $\mathrm{q}$ divided by the sum of i's relations; $M_{j p}$ interaction with q divided by the strongest of $j$ 's relationships with anyone, $q \neq i, j$ )

Network Strength. Followed on the research of Kratzer et al. (2010), we used Eq. (4) to illustrate how to calculate the coefficient of network strength. A scale of 0 to 6 is used in this research.

$$
\text { NS }\left(n_{i}\right)=\frac{\left(\sum_{v i \neq i} L \cdot s\right)}{\sum_{V i \neq 1} 1 \cdot s_{\max }} E q .(4)
$$

( $\mathrm{S}_{\max }$ is the maximum strength 6; $\mathrm{L}$ is the value of direct links ( 0 or 1 ); $S$ is the contacting strength ( 0 to 6$)$ )

\subsubsection{Team creativity}

Team creativity was measured via a 7-point Likert scale based on items developed by Kratzer et al. (2008) which comprised items such as novelty, originality, usefulness and flexibility. The results show a Cronbach's Alpha coefficient of 0.81 , which proves a high level of scale reliability. Next, we calculated the value of team creativity from the collected data. To do this we counted individuals' creativity scores by averaging the scores of these 4 items. Then we calculated the scores of each teams' creativity, by summing the values of individuals' creativity and dividing by the total number of team members.

\subsubsection{Controls}

We controlled two variables namely team size and team experience to eliminate their influence on the results. Specifically, we controlled team size because literature on teams has shown that size has a significant influence on team creativity. For example, Leenders et al. (2003) found that team size has negative effect on creativity. Team experience is included as a control variable, as pervious scholars have found there is a curvilinear relationship between that organizational tenure and team engagement in the creative processes (Gilson \& Shalley, 2004). In this research, team experience was measured by calculating the average tenure of leaders and members in teams.

\subsection{Analysis and results}

In this research, there are four independent variables (density, centralization, efficiency and strength), one dependent variable (team creativity) and two control variable (team size and experience). In order to explore the correlations among these variables we conduct a correlation analysis using a one-tailed test as it can help us predict whether a relationship exists and if so it can determine the direction of that relationship (Kutner et al., 2004). We also used hierarchical regression analysis to test hypotheses as this study conducts multilevel analysis (Tabachnick \& Fidell, 2007). The descriptive statistics for the dataset are reported in Table 5: the mean value of team creativity is 5.62 (on a scale from 1 to 7 ), and the mean network density, centralization, efficiency and strength are $0.43,0.21,0.51$ and 0.58 correspondingly (on a scale from 0 to 1 ).

The matrix in Table 5 also shows the results of correlation analysis on team-level data and reveals the relationship among these variables. We can see that network density is significantly correlated with network strength $(\mathrm{r}=.37 ; p<.05)$, and network centralization related to network efficiency $(\mathrm{r}=.43 ; p<.05)$, which would affect the results of a regression analysis due to multicollinearity problems. However, this research also found that the values of Variable Inflation Factor (VIF) (which is an indicator to quantify the severity of the multicollinearity) among all variables are below 1.5. This suggests that the strength of the relationship is not enough to be overly concerned when estimating the regression coefficients (Kutner et al., 2004). 
Table 5. Descriptive statistics and Correlations ${ }^{*} \mathrm{p}<.05{ }^{* *} \mathrm{p}<.01$

\begin{tabular}{|c|c|c|c|c|c|c|c|c|}
\hline Variables & Mean & $\mathrm{SD}$ & ND & $\mathrm{NC}$ & $\mathrm{NE}$ & NS & TS & $\mathrm{TE}$ \\
\hline \multicolumn{9}{|l|}{ Dependent variable } \\
\hline Team Creativity (TC) & 5.62 & 0.68 & $.72^{\star *}$ & $-.54^{* *}$ & -.16 & $.48^{*}$ & $-.47^{*}$ & .02 \\
\hline \multicolumn{9}{|l|}{ Independent variables } \\
\hline Network Density (ND) & 0.44 & 0.06 & - & -.31 & -.20 & $.37^{\star}$ & -.30 & -.01 \\
\hline Network Centralization (NC) & 0.20 & 0.05 & & - & $.42^{*}$ & -.14 & .05 & -.07 \\
\hline Network Efficiency (NE) & 0.51 & 0.08 & & & - & -.24 & -.13 & .22 \\
\hline Network Strength (NS) & 0.57 & 0.11 & & & & - & -.23 & .13 \\
\hline \multicolumn{9}{|l|}{ Control variables } \\
\hline Team Size (TS) & 7.18 & 1.56 & & & & & - & -.23 \\
\hline Team Experience (TE) & 3.71 & 0.81 & & & & & & - \\
\hline
\end{tabular}

Table 6 illustrates the results of the regression analysis with team creativity as the dependent variable. Model 1 in this table shows the basic model with only control variables $(=.15)$, which explains $15 \%$ of the variation in team creativity.

Table 6. Hierarchical regression analysis with dependent variable team creativity ${ }^{*} \mathrm{p}<.05,{ }^{* *} \mathrm{p}<.01,{ }^{* * *} \mathrm{p}<.001$

\begin{tabular}{|c|c|c|c|c|c|c|c|}
\hline Independent Variables & Model 1 & Model 2 & Model 3 & Model 4 & Model 5 & Model 6 & Model 7 \\
\hline \multicolumn{8}{|l|}{ Controls } \\
\hline Team size & $-.49^{*}$ & -.29 & $-.32^{\star}$ & $-.31^{*}$ & -.30 & -.18 & $-.18^{\star \star}$ \\
\hline Team experience & -.10 & -.05 & -.08 & -.10 & -.10 & -.06 & \\
\hline \multicolumn{8}{|l|}{ Predictors } \\
\hline Network density & & $.63^{* *}$ & $051^{* *}$ & $.52^{\star *}$ & $.44^{*}$ & $.37^{* *}$ & $.36^{* *}$ \\
\hline Network centralization & & & $-.38^{*}$ & $-.41^{*}$ & $-.38^{*}$ & $-.35^{\star *}$ & $-3.14^{\star \star}$ \\
\hline Network efficiency & & & & .10 & .02 & .06 & \\
\hline Network strength & & & & & .21 & $6.27^{\star *}$ & $4.40^{* * *}$ \\
\hline \multirow[t]{2}{*}{ Strength squared } & & & & & & $-6.03^{* *}$ & $-4.26^{* *}$ \\
\hline & .23 & .60 & .72 & .72 & .75 & .89 & .88 \\
\hline Adjusted & .15 & .52 & .65 & .63 & .65 & .83 & .84 \\
\hline $\mathrm{F}$ & 2.81 & $8.58^{\star *}$ & $10.64^{* * *}$ & $8.28^{\star *}$ & $7.64^{\star *}$ & $15.43^{* * *}$ & $23.50^{\star * \star}$ \\
\hline
\end{tabular}

Model 2 refers to network density, a predictor variable, which is used to test Hypothesis 1 (density in a shared leadership network is positivity related to team creativity). The result shows that there is a positive statistically significant correlation between network density and team creativity $(\beta=.63 ; p<.01)$, implying that higher levels of team creativity would exist in shared leadership networks with more links among team members. Thus, our Hypothesis 1 is fully supported by this result. The control variables and network density explains $52 \%$ of the variance.

The independent variable network centralization was added to the equation and is listed in Model 3 of Table 6. The result supports
Hypothesis 2 (centralization in a shared leadership network is negatively related to team creativity) due to a negative statistically significant correlation between network centralization and team creativity $(\beta=$ $-.38 ; p<.05)$, suggesting that a more centralized network with higher variance has unequal distributions about leadership within teams tents to hinder creativity. The of this model accounted for $65 \%$ of the variance in team creativity.

Unexpectedly, when we entered network efficiency (shown in Model 4 in Table 6), it did not achieve statistical significance. In other words, we cannot find a significant relationship between network efficiency and team creativity $(\beta=.10 ; p>.05)$. Therefore, Hypothesis 3 (efficiency 
in a shared leadership network is positivity related to team creativity) is not supported. Moreover, when we added the network efficiency variable, the value of (.63) in Model 4 reduced by .02, compared to the value of (.65) in Model 3. This implies that network efficiency plays a negative role in explaining the variance in team creativity.

Next we tested Hypothesis 4: there is an inverted U-shaped relationship between strength in shared leadership network and team creativity. To do this, network strength was entered (see Model 5 in Table 6). This was found not to be correlated to team creativity $(\beta=.21 ; p>.05)$. This model accounts for $65 \%$ of the variance in team creativity. Next the quadratic term of network strength (i.e., network strength squared) was added (see Model 6). Then, we found it has a significant and positive quadratic effect on team creativity $(\beta=6.03 ; p<.01)$, during which the value of adjusted increased from .65 in Model 5 to .83 in Model 6. It means an additional $18 \%$ of the variance increases the linear effect. This negative quadratic term associated with a positive linear term $(\beta=6.27 ; p<0.01)$ implies that there is a predominantly positive, concave downward curve (Aiken et al., 1991). We plotted this interaction in Figure 4: the quadratic fit of network strength in predicting team creativity, which reveals that team creativity rose gradually with the growth of network strength, nevertheless after team creativity peaked with the value of strength around 0.55 , it decreased as network strength increased. The inverted curve supports Hypothesis 4 .

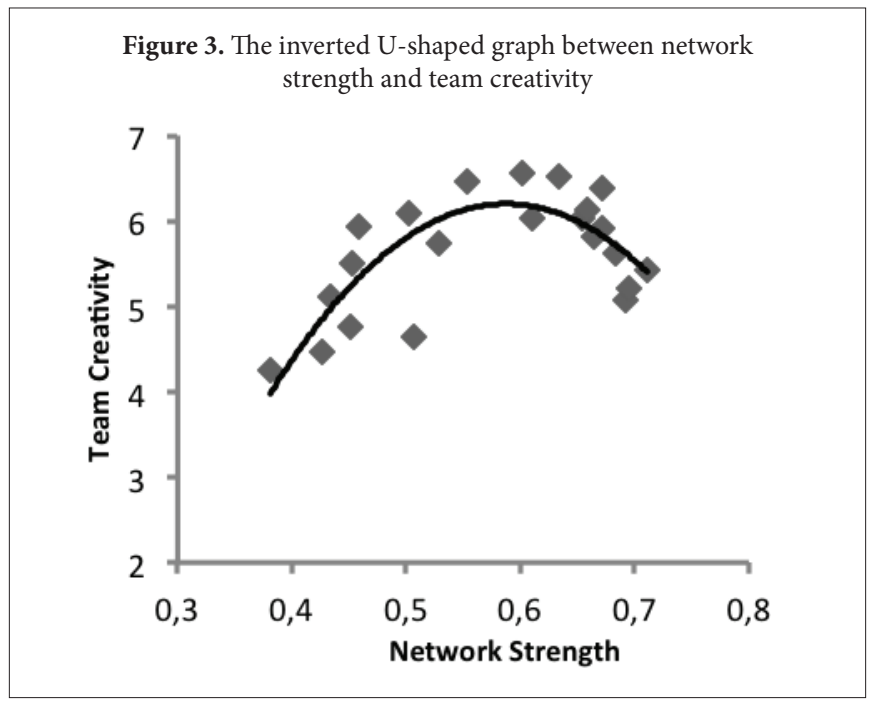

Model 7 in Table 6, is a full model including the control variables and all the predictor variables. This explains $83 \%$ of the variance in team creativity. Model 8 in Table 6 is an adjusted full model that contains only the significant variables with the value of adjusted being .84 .

In summary, this research proved that shared leadership network density is positively associated with team creativity, as opposed to network centralization that exerts a negative influence on it. Moreover, while we found that there is no evidence to support the positive correlation between network efficiency and team creativity, we demonstrated an inverted U-shaped between strength and team creativity in shared leadership networks.

\section{Discussion}

The result of this study offers support for the hypothesized positive relationship between network density in shared leadership structures and team creativity. It suggests that team creativity is increased where high levels of density in shared leadership networks exist. Here large number of interactions among team members can effectively accelerate the process of information flow, and consequently, promote team creativity. This finding is consistent with other studies such as Lee et al. (2015), who proposed that shared leadership exerts a positive effects on knowledge sharing and consequently on team creativity.

According to our analysis, the relationship between centralization in shared leadership networks and team creativity is negative as expected. This confirms earlier studies which also found a negative relationship between network centralization and team creativity (e.g., Leenders et al., 2003). This research focuses on leadership behaviors that are distributed among team members. The result implies that in shared leadership networks where centralization is strong, the level of interdependence and cooperation among team members is reduced, which hinders team creativity. In contrast, when networks have a lower level of centralization, larger members are engaged in the leadership process, as a result, accountability for the team performance is more equally distributed across the whole team which in turn helps to develop creative solutions to problems.

Our findings do not support the hypothesis that efficiency in shared leadership networks is positively related to team creativity. To our surprise, there is no statistical correlation between them. It means that efficient information exchange in shared leadership networks does not influence the creative performance of the team. This contradicts the findings of Leenders et al. (2003) who discovered that moderate efficiency in communication networks enhances the creativity of teams.

Finally, as expected we found that in shared leadership networks, there is an optimum level of strength in a network which contributes to creativity, however after this point increased strength levels may lead to the tendency to impede team creativity. This finding is broadly consistent with strength-of-weak-ties theory as outlined by Granovetter (1973) and those of researchers who have argued for an inverted U-shaped relationship between strength and team creativity (e.g., Kratzer et al., 2010; Perry-Smith \& Shalley, 2003). Our findings have extended their work by demonstrating that a curvilinear relationship exists between network strength and team creativity in shared leadership networks. It suggests that in shared leadership networks, as links between two individuals grow stronger, group members come to know each other; and then, viewpoints held by others become shared and perhaps redundant. As a result, during this process team creativity increases gradually, after reaching the peak value and then downward trend appears.

\section{Conclusions and future work}

Previous studies have proven that a team does well when it relies on leadership provided by the team as a whole instead of being led by a 
single individual. With more focus on shared leadership, researchers have shown that this model has a positive influence on team performance, effectiveness and important team processes. Our study added to this conversation by exploring the relationship between shared leadership and team creativity. We found that network density, centralization and strength are all associated with team creativity in shared leadership networks. We also learned that network efficiency is not related to team creativity. This implies that high density, low centralization and appropriate strength of shared leadership networks promote team creativity for organizations in industries. These findings are important for many reasons. First, our research expands and deepens the debate in the area of shared leadership area by collecting empirical data in a new domain. Second, our findings have practical relevance for senior managers in industry who seek to implement best practice design structured in organizations. Third, as our study collected real data from functioning design teams (as opposed to an artificial setting in a laboratory) this study crosses the chasm from academia to industry.

However, this research is not without its limitations. First, we understand that self-report studies rely on a certain level of introspective ability from respondents to answer questions and despite all efforts to increase validity and reliability they may also be prone to response bias which could lead to deviation in the data. To combat this, future studies might consider including data from external assessments such as independent experts as well as self-reported data from internal respondents. Second, this study focused on two types of engineering design teams: chemical engineering and mechanical engineering employing a sample of 22 design teams in total. As this sample is not representative of all engineering design teams, the results do not accurately measure the entire population. Hence, future research could adopt a wider perspective and include more data from teams representing different engineering fields. Thirdly, as shared leadership networks are dynamic and subject to change as time goes by, particularly when new relations have just been built a longitudinal study may justified. Finally, future research could focus on examining whether there are some potential mediating factors in the relationship between shared leadership and team performance, effectiveness or team creativity. In this regard constructs such as team cooperation or team empowerment may be considered.

\section{References}

Aiken, L. S., West, S. G., \& Reno, R. R. (1991). Multiple regression: Testing and interpreting interactions: Sage.

Baer, M. (2010). The strength-of-weak-ties perspective on creativity: a comprehensive examination and extension. Journal of applied psychology, 95(3), 592.

Balkundi, P., \& Kilduff, M. (2006). The ties that lead: A social network approach to leadership. The Leadership Quarterly, 17(4), 419-439.
Bergman, J. Z., Rentsch, J. R., Small, E. E., Davenport, S. W., \& Bergman, S. M. (2012). The shared leadership process in decision-making teams. The Journal of social psychology, 152(1), 17-42.

Borgatti, S. P., Everett, M. G., \& Freeman, L. C. (2002). Ucinet for Windows: Software for social network analysis.

Burt, R. S. (2009). Structural holes: The social structure of competition: Harvard university press.

Carson, J. B., Tesluk, P. E., \& Marrone, J. A. (2007). Shared leadership in teams: An investigation of antecedent conditions and performance. Academy of management Journal, 50(5), 1217-1234.

Cox, J. F., Pearce, C. L., \& Perry, M. L. (2003). Toward a model of shared leadership and distributed influence in the innovation process: How shared leadership can enhance new product development team dynamics and effectiveness. Shared leadership: Reframing the hows and whys of leadership, 4876.

Day, D. V., Gronn, P., \& Salas, E. (2004). Leadership capacity in teams. The Leadership Quarterly, 15(6), 857-880.

Ensley, M. D., Hmieleski, K. M., \& Pearce, C. L. (2006). The importance of vertical and shared leadership within new venture top management teams: Implications for the performance of startups. The Leadership Quarterly, 17(3), 217-231.

Flap, H., \& Völker, B. (2001). Goal specific social capital and job satisfaction: Effects of different types of networks on instrumental and social aspects of work. Social networks, 23(4), 297-320.

Fransen, K., Van Puyenbroeck, S., Loughead, T. M., Vanbeselaere, N., De Cuyper, B., Broek, G. V., \& Boen, F. (2015). Who takes the lead? Social network analysis as a pioneering tool to investigate shared leadership within sports teams. Social networks, 43, 28-38.

Freeman, L. (2004). The development of social network analysis. A Study in the Sociology of Science.

Freeman, L. C. (1979). Centrality in social networks conceptual clarification. Social networks, 1(3), 215-239.

Gehani, R. (2011). Individual Creativity and the influence of mindful leaders on enterprise innovation. Journal of technology management \& innovation, 6(3), 82-92.

Gilson, L. L., \& Shalley, C. E. (2004). A little creativity goes a long way: An examination of teams' engagement in creative processes. Journal of management, 30(4), 453-470.

Granovetter, M. S. (1973). The strength of weak ties. American journal of sociology, 1360-1380. 
Hackman, M. Z., \& Johnson, C. E. (2013). Leadership: A communication perspective: Waveland Press.

Hooker, C., \& Csikszentmihalyi, M. (2003). Flow, creativity, and shared leadership. Shared leadership: Reframing the hows and whys of leadership, 217-234.

Hoppe, B., \& Reinelt, C. (2010). Social network analysis and the evaluation of leadership networks. The Leadership Quarterly, 21(4), 600-619.

Klein, K. J., Ziegert, J. C., Knight, A. P., \& Xiao, Y. (2006). Dynamic delegation: Shared, hierarchical, and deindividualized leadership in extreme action teams. Administrative science quarterly, 51(4), 590-621.

Kozlowski, S. W., \& Bell, B. S. (2003). Work groups and teams in organizations. Handbook of psychology.

Kratzer, J., Leenders, R. T. A., \& Van Engelen, J. M. (2008). The social structure of leadership and creativity in engineering design teams: An empirical analysis. International Journal of Project Management, 25(4), 269-286.

Kratzer, J., Leenders, R. T. A., \& Van Engelen, J. M. (2010). The social network among engineering design teams and their creativity: A case study among teams in two product development programs. International Journal of Project Management, 28(5), 428-436.

Kutner, M. H., Nachtsheim, C., \& Neter, J. (2004). Applied linear regression models: McGraw-Hill/Irwin.

Latora, V., \& Marchiori, M. (2001). Efficient behavior of small-world networks. Physical review letters, 87(19), 198701.

Lee, D. S., Lee, K. C., \& Seo, Y. W. (2015). An analysis of shared leadership, diversity, and team creativity in an e-learning environment. Computers in Human Behavior, 42, 47-56.

Leenders, R. T. A., Van Engelen, J. M., \& Kratzer, J. (2003). Virtuality, communication, and new product team creativity: a social network perspective. Journal of Engineering and Technology Management, 20(1), 69-92.

Lessard, C., \& Lessard, J. (2007). Project management for engineering design. Synthesis Lectures on Engineering, 2(1), 1-110.

Maloney, M. M., Johnson, S. G., \& Zellmer-Bruhn, M. E. (2010). Assessing group-level constructs under missing data conditions: A Monte Carlo simulation. Small Group Research, 41(3), 281-307.

McEvily, B., Perrone, V., \& Zaheer, A. (2003). Trust as an organizing principle. Organization science, 14(1), 91-103.

Mehra, A., Smith, B. R., Dixon, A. L., \& Robertson, B. (2006). Distributed leadership in teams: The network of leadership perceptions and team performance. The Leadership Quarterly, 17(3), 232-245.
Molm, L. D. (1994). Dependence and risk: Transforming the structure of social exchange. Social Psychology Quarterly, 163-176.

Muethel, M., \& Hoegl, M. (2013). Shared leadership effectiveness in independent professional teams. European Management Journal, 31(4), 423-432.

Pandey, S., \& Sharma, R. (2009). Organizational factors for exploration and exploitation. Journal of technology management \& innovation, 4(1), 48-58.

Pastor, J. C., \& Mayo, M. (2002). Shared leadership in work teams: A social network approach: Instituto de Empresa, Area of Economic Environment.

Pearce, C. L. (2004). The future of leadership: Combining vertical and shared leadership to transform knowledge work. The Academy of Management Executive, 18(1), 47-57.

Pearce, C. L., \& Conger, J. A. (2002). Shared leadership: Reframing the hows and whys of leadership: Sage Publications.

Pearce, C. L., \& Sims, J. H. P. (2002). Vertical versus shared leadership as predictors of the effectiveness of change management teams: An examination of aversive, directive, transactional, transformational, and empowering leader behaviors. Group dynamics: Theory, research, and practice, 6(2), 172.

Pearce, C. L., Yoo, Y., \& Alavi, M. (2004). Leadership, social work, and virtual teams. Improving Leadership in Nonprofit Organizations, edited by Ronald E. Riggio and Sarah Smith Orr, 180-199.

Perry-Smith, J. E., \& Shalley, C. E. (2003). The social side of creativity: A static and dynamic social network perspective. Academy of management review, 28(1), 89-106.

Seers, A., Keller, T., \& Wilkerson, J. (2003). Can team members share leadership. Shared leadership: Reframing the hows and whys of leadership, 77-102.

Shane Wood, M., \& Fields, D. (2007). Exploring the impact of shared leadership on management team member job outcomes. Baltic Journal of Management, 2(3), 251-272.

Small, E. E., \& Rentsch, J. R. (2015). Shared leadership in teams. Journal of Personnel Psychology.

Sparrowe, R. T., Liden, R. C., Wayne, S. J., \& Kraimer, M. L. (2001). Social networks and the performance of individuals and groups. Academy of management Journal, 44(2), 316-325.

Stogdill, R. M. (1948). Personal factors associated with leadership: A survey of the literature. The Journal of psychology, 25(1), 35-71. 
Tabachnick, B., \& Fidell, L. (2007). Using Multivariate Statistics., 5th edn.(Allyn and Bacon: Boston, MA.).

Wasserman, S., \& Faust, K. (1994). Social network analysis: Methods and applications (Vol. 8): Cambridge university press.
Yuan, Y. C., Fulk, J., Monge, P. R., \& Contractor, N. (2009). Expertise directory development, shared task interdependence, and strength of communication network ties as multilevel predictors of expertise exchange in transactive memory work groups. Communication Research.

Zaccaro, S. J., Rittman, A. L., \& Marks, M. A. (2002). Team leadership. The Leadership Quarterly, 12(4), 451-483. 